\title{
Ultrastructures of the Epithelial Basement Membrane and the Subepithelial Capillaries in Rabbit Palatine Tonsils
}

\author{
Toshihiko Higashikawa ${ }^{1}$, Osamu OHTani ${ }^{2}$ and Yu Masuda ${ }^{1}$ \\ Department of Otolaryngology ${ }^{1}$ and Department of Anatomy ${ }^{2}$, Okayama University School of Medicine, Okayama, Japan \\ Received June 19, 1989
}

\begin{abstract}
Summary. The ultrastructure of both the epithelial basement membrane and the subepithelial capillaries in rabbit tonsils was investigated using light and transmission electron microscopy of sections, and scanning electron microscopy of alkali-water macerated tissues. The basement membrane of the crypt epithelium was seen to consist of the lamina lucida, lamina densa and lamina fibroreticularis. The lamina fibroreticularis is made up of both fine and thick collagen fibrils. The basement membrane possesses numerous pores $(0.5-20 \mu \mathrm{m}$ in diameter) through which free cells migrate. The basement membrane overlying the follicle protrudes hemispherically towards the crypt lumen, while that over the interfollicular area forms many papillary projections. The capillaries are surrounded by collagen fibrillar sheaths invariably located below the collagen fibrillar sheet of the epithelial basement membrane. The capillaries immediately below the crypt epithelium, including switch-back loops of capillaries in the papillae, are fenestrated sinusoids (20-40 $\mu \mathrm{m}$ in diameter). Plasma cells, lymphocytes and macrophages are numerously gathered around the capillaries. Possible functional relations between these free cells and the fenestrated sinusoids are discussed.
\end{abstract}

Palatine tonsils, a representative of gut-associated lymphoid tissues (COOPER et al., 1967), recognize and respond to antigens in the gut lumen (ANDERSON, 1974; OWEN and NeMANIC, 1978; HowIE, 1980). It is generally accepted that the crypt epithelium infiltrated with free cells is responsible for recognizing antigens. However, the structure through which the free cells migrate remains to be studied. On the other hand, our previous studies by scanning electron microscopy (SEM) of vascular corrosion casts of the palatine tonsils in rabbits (TERASAWA et al., 1988) and in the human (OHTANI et al., 1989) have revealed that the capillaries immediately below the crypt epithelium show a sinusoidal appearance. However, little is known not only about the ultrastructure of the subepithelial capillaries but also about their relationship to the epithelial basement membrane. We therefore examined the ultrastructure of the epithelial basement membrane and the subepithelial capillaries by transmission electron microscopy (TEM). In order to visualize the organization of the basement membrane of the crypt epithelium and its relationship to the subepithelial capillaries, we also employed the alkali-water maceration/SEM method (OHTANI, 1987) which allows examination of the three-dimensional organization of the collagen fibrillar network.

Our results indicate that the epithelial basement membrane is highly porous and that the subepithelial capillaries with fenestrations exist immediately below the epithelial basement membrane. The functional significance of the basement membrane porosity and that of the subepithelial sinusoids with fenestrations is discussed in connection with the immune responses of the tonsils and with the differentiation of high endothelial venules (HEVs).

\section{MATERIALS AND METHODS}

Eight adult healthy rabbits (2-4 kg body weight) were used. All animals were fed a combination of solid food for experimental animals (ARC4; Oriental East, Tokyo) with free access to water. One animal was used for light microscopy of sections, two for SEM of alkali-water macerated tissues, and five for TEM.

The animals were killed with intravenous injections of overdoses of pentobarbital sodium (Nembutal; Abbott Lab., North Chicago). The thoracic cavity was opened, and a polyethylene tube was inserted through the left ventricle into the ascending aorta. 
The right atrium was cut open, and the abdominal aorta and right and left subclavian arteries were ligated.

\section{Light microscopy}

The animal was perfused with $10 \%$ formalin in $0.1 \mathrm{M}$ phosphate buffer (PB; $\mathrm{pH} 7.2)$ or with Bouin's fixatives. The palatine tonsils were excised, dehydrated through a series of graded concentrations of ethanol, and embedded either in paraffin or in Technovit 7100 (Kulzer, Friedrichsdorf). Paraffin sections were stained either with hematoxylin and eosin or with aldehydefuchsin followed by Masson-Goldner's trichrome staining (GOLDNER, 1938). Technovit sections were stained with toluidine blue ( $\mathrm{pH}$ 7.2). The preparations were observed and photographed with a BH-2 photomicroscope equipped with PM-10ADS (Olympus, Tokyo).

\section{Scanning electron microscopy of macerated tissues}

In order to reveal the collagen fibrillar network immediately below the crypt epithelium of the tonsil, we employed the alkali-water maceration/SEM method (OHTANI, 1987; OHTANi et al., 1988).
After perfusion with saline, the animals were perfusion-fixed with $2.5 \%$ glutaraldehyde in $0.1 \mathrm{M} \mathrm{PB}$ $(\mathrm{pH}$ 7.2). The tonsils were excised, immersed in the same fixatives for a day, and placed in $2 \mathrm{~N}-\mathrm{NaOH}$ for 4 days at room temperature $\left(25-30^{\circ} \mathrm{C}\right)$. They were then washed in distilled water for 3-4 days until they took on a whitish, translucent appearance. The samples thus obtained were conductive-stained with 1.0\% tannic acid and $1.0 \% \mathrm{OsO}_{4}$ (Murakami, 1973). They were dehydrated through graded concentrations of ethanol and critical point-dried using liquid $\mathrm{CO}_{2}$. The preparations were coated with platinum-palladium (2-3 nm thick) and observed under either a JSM-U3 (JEOL, Tokyo) or S-2300 (Hitachi, Tokyo) scanning electron microscope with an accelerating voltage of $15 \mathrm{kV}$.

\section{Transmission electron microscopy}

Following the perfusion with saline, the animals were perfusion-fixed with $2.5 \%$ glutaraldehyde in $0.1 \mathrm{M} \mathrm{PB}$ (pH 7.2). The tonsils excised were sliced into pieces, washed in $0.1 \mathrm{M} \mathrm{PB}$ ( $\mathrm{pH} 7.2$ ), and post-fixed with $1.0 \%$ $\mathrm{OsO}_{4}$ in $0.1 \mathrm{M} \mathrm{PB}$ (pH 7.2). The pieces were dehydrated

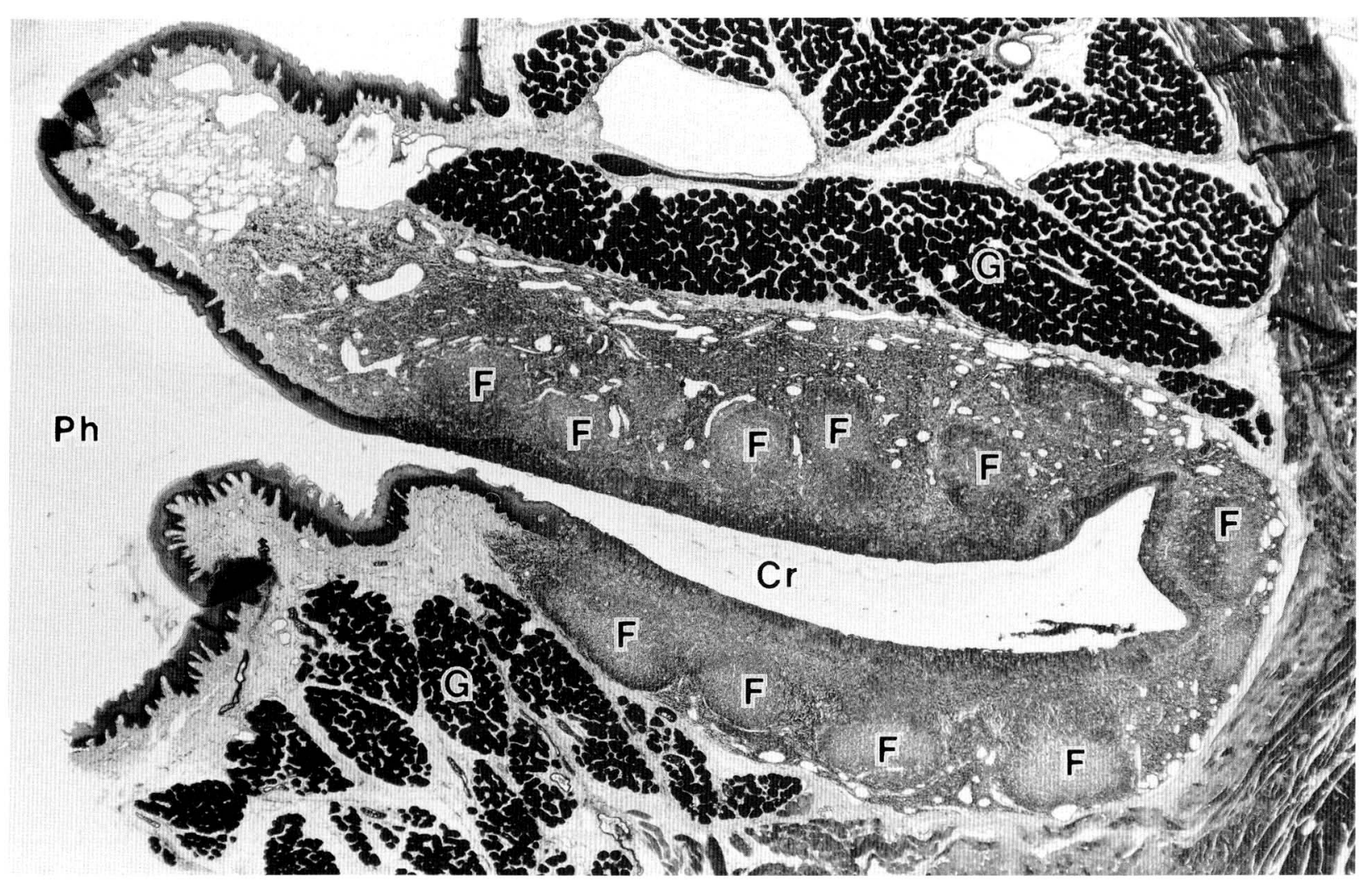

Fig. 1. A light micrograph of a rabbit palatine tonsil (aldehyde-fuchsin plus Masson-Goldner staining). There are many follicles $(F)$ aligned in a monolayer along the crypt $(\mathrm{Cr})$. Ph pharynx, $G$ gland. $\times 40$ 
through graded concentrations of ethanol and embedded in Epon (LuFT, 1961). Thin sections were doublestained with uranyl and lead, and observed under an H-300 transmission electron microscope (Hitachi, Tokyo). Semithin sections were stained with $0.1 \%$ toluidine blue in $0.1 \mathrm{M} \mathrm{PB}(\mathrm{pH} 7.2)$ and observed under a light microscope.

\section{RESULTS}

\section{Light microscopy}

The palatine tonsil of the rabbit possesses a crypt around which many lymphoid follicles are arranged in a monolayer (Fig. 1). The crypt epithelium is infiltrated by many lymphocytes and other free cells such as macrophages, thus forming a lymphoepithelial symbiosis (coined by FioretTI, 1961) (Fig. 2). The lymphoepithelial symbiosis was most prominent in the crypt epithelium directly overlying the follicle
(Fig. 2a). The typical stratified epithelium without free cell infiltration was restricted to the area around the orifice of the crypt. The capillaries below the crypt epithelium over the follicle showed various calibers and irregular shapes (Fig. 2a). There were many papillae projecting into the crypt epithelium, except for the epithelium immediately above the follicle (Fig. 2b, c). Light microscopy of the sections parallel to the crypt lumen showed transversely cut papillae that were delimited by the epithelial basement membranes (Fig. 2c).

\section{Scanning electron microscopy of collagen fibrillar network}

Maceration with alkali plus water at room temperature eliminated cellular elements with the lamina densa of the basement membrane, and thus exposed the subepithelial collagen fibrillar network of the tonsil (Fig. 3). The collagen fibrils observed under the
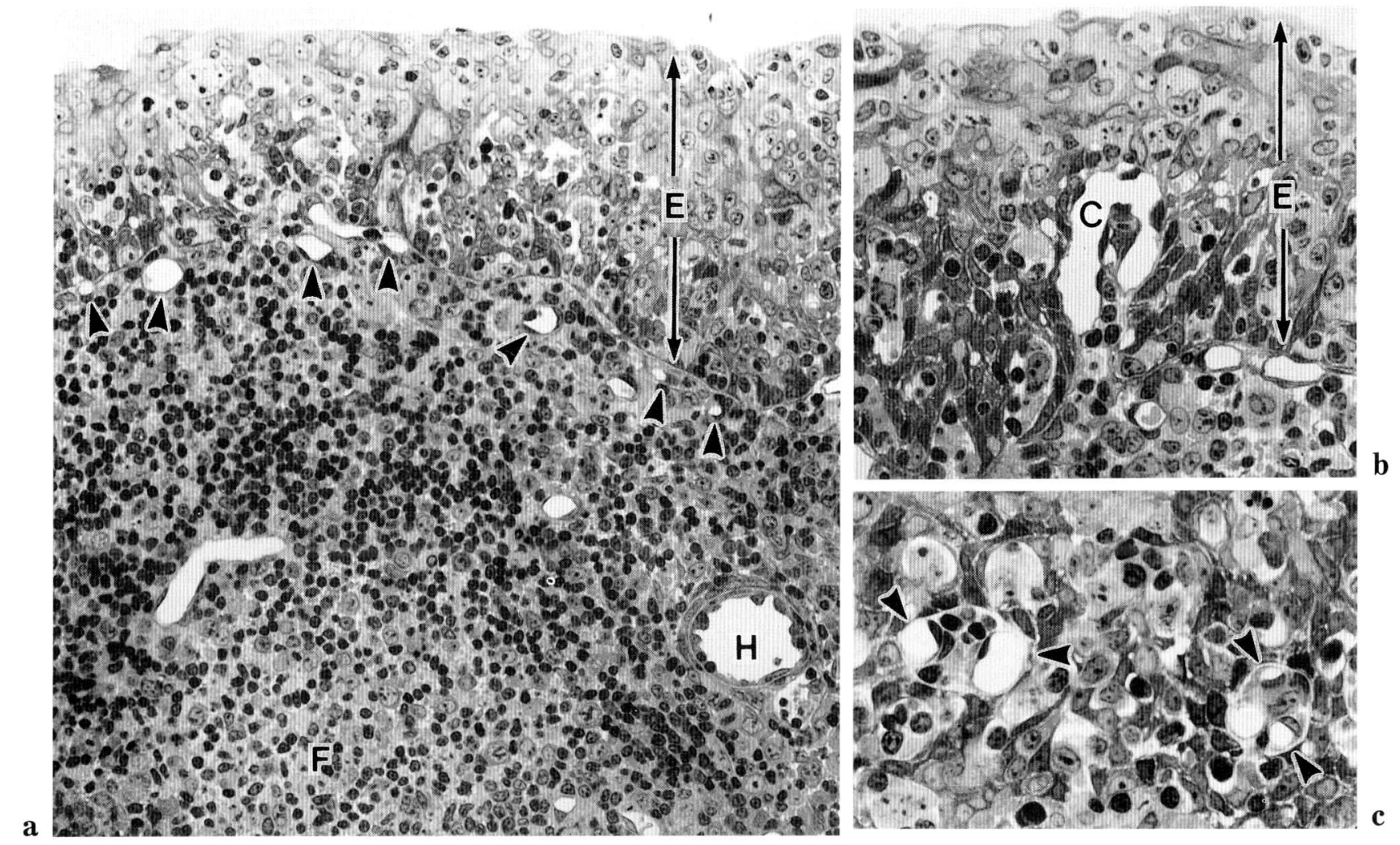

Fig. 2. Light micrographs of a rabbit palatine tonsil (toluidine-blue staining). a. The crypt epithelium $(E)$ is highly reticulated through the infiltration of free cells. Immediately below the epithelium are capillaries (arrowheads) of various sizes. b. A papilla that contains a loop of a capillary $(C)$ projects into the crypt epithelium $(E)$ overlying the interfollicular area. c. A section parallel to the epithelial surface over the interfollicular area shows round or oval sections of papillae surrounded by epithelial cells and free cells. Each section of the papilla contains a pair of capillaries (arrowheads). $F$ follicle, $H$ HEV. a: $\times 300$, b and c: $\times 400$ 

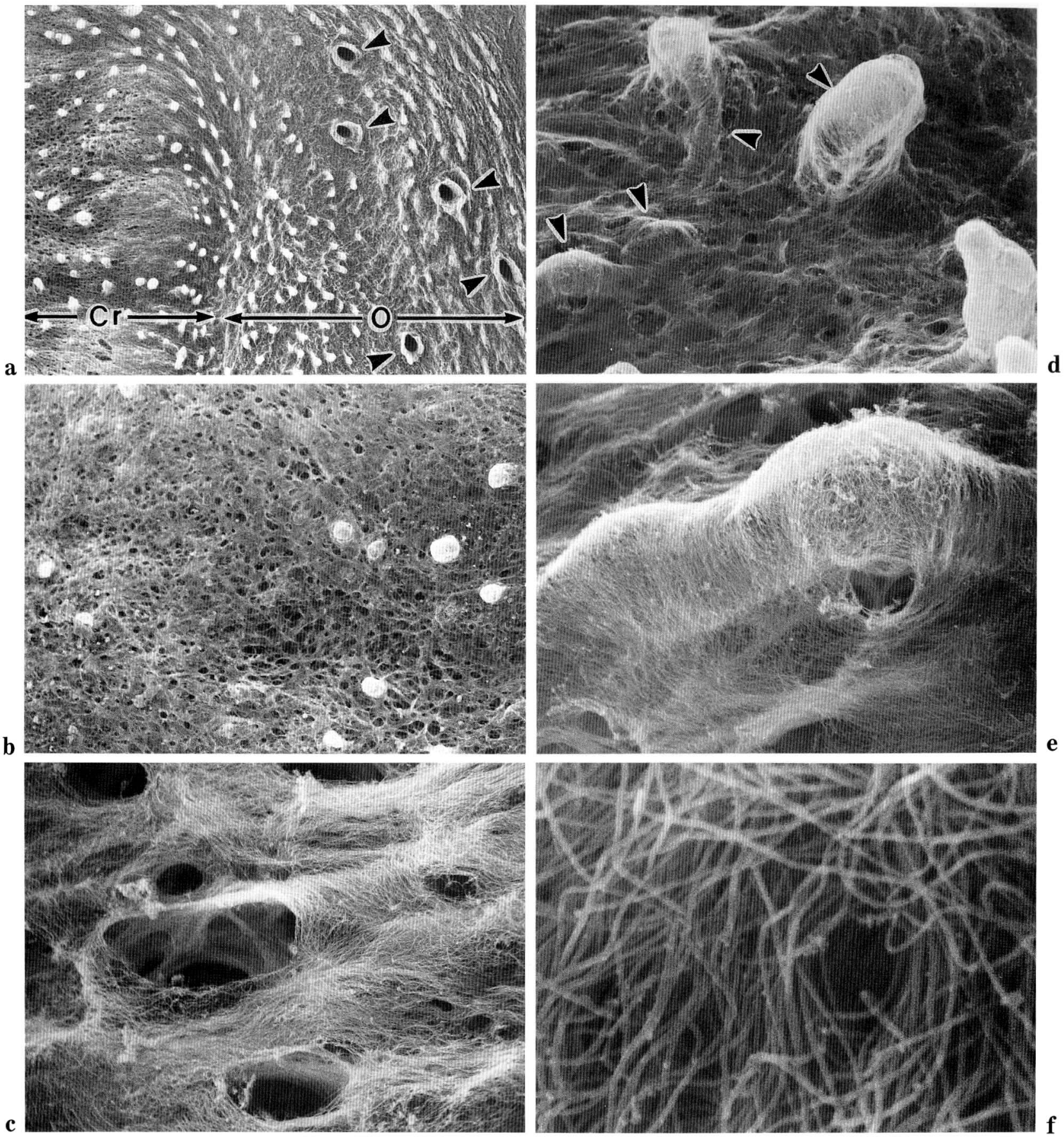

Fig. 3. SEM views of the collagen fibrillar network of the epithelial basement membrane with numerous pores $(0.5-2.0 \mu \mathrm{m}$ in diameter) of a rabbit palatine tonsil. a. The network at the orifice of the crypt $(O)$ has many papillae and holes (arrowheads) for ducts of glands, while that along the crypt $(\mathrm{Cr})$ is rather smooth with scattered papillae. b. The collagen fibrillar network in the deep part of the crypt shows numerous pores and scattered papillae. c. A higher magnification of b. d. Collagen fibrillar sheaths for accommodating the subepithelial capillaries push up the overlying collagen fibrillar sheet of the epithelial basement membrane (indicated by arrowheads). e. A higher magnification of part of $\mathbf{d}$. f. A higher magnification of the collagen fibrillar network of the epithelial basement membrane. a: $\times 50, \mathrm{~b}: \times 130, \mathrm{c}: \times 1,700, \mathrm{~d}: \times 500$, e: $\times 1,700, \mathrm{f}: \times 17,500$ 

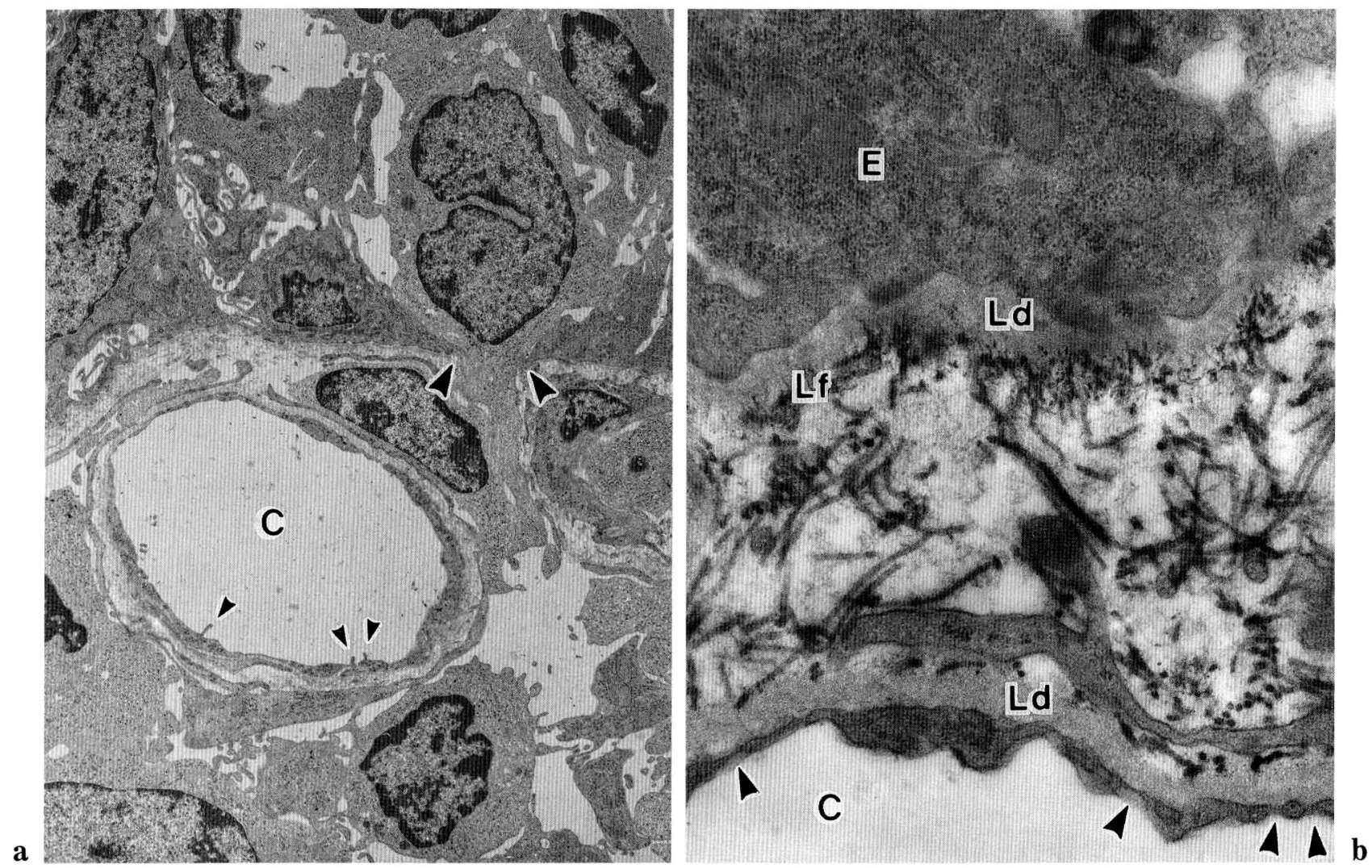

Fig. 4. TEM views of the crypt epithelium and subepithelial capillary $(C)$. a. A free cell is wedged in the interruption (between large arrowheads) of the basement membrane of the epithelium. The endothelium of the subepithelial capillary is extremely thin, but has microvilli (small arrowheads) projecting into the lumen. b. The basement membrane of the crypt epithelium $(E)$ consists of the lamina lucida, lamina densa $(L d)$ and lamina fibroreticularis $(L f)$ which is made up of thin (about $10 \mathrm{~nm}$ diameter) and thick (60-80 nm diameter) collagen fibrils. The subepithelial capillary is surrounded by the basal lamina densa $(L d)$ and collagen fibrils. The endothelium is attenuated and has many fenestrations with diaphragms (arrowheads). a: $\times 4,800, \mathrm{~b}: \times 25,000$

SEM were $60-80 \mathrm{~nm}$ in diameter (Fig. 3f). The collagen fibrillar network located immediately below the crypt epithelium possessed numerous round or elliptical pores (0.5-2.0 $\mu \mathrm{m}$ in diameter) (Fig. 3a-d). The collagen fibrillar network below the crypt epithelium which overlay the follicle was smooth but slightly convex towards the crypt, while that over the interfollicular area possessed finger-like papillae projecting towards the crypt lumen (Fig. 3a, b). The collagen fibrillar network delimiting the papillae had few pores. The short papillae located close to the follicle, however, possessed some pores in the collagen fibrillar network around the shafts and tips of the papillae. The collagen fibrillar sheaths surrounding the blood vessels were located below the collagen fibrils constituting the epithelial basement membrane
(Fig. 3d, e). Around the orifice of the crypt were many openings of tunnels for accommodating the ducts of glands. Here also were many papillary projections, but they were broader than those seen below the crypt epithelium (Fig. 3a).

\section{Transmission electron microscopy}

The crypt epithelium was highly infiltrated by numerous lymphocytes, plasma cells, macrophages and other free cells. The basal laminae of the crypt epithelia showed many interruptions in which lymphocytes and other free cells were wedged (Fig. 4a). The basement membrane consists of the lamina lucida, lamina densa and lamina fibroreticularis. The lamina fibroreticularis comprises at least two kinds of collagen fibrils: one 

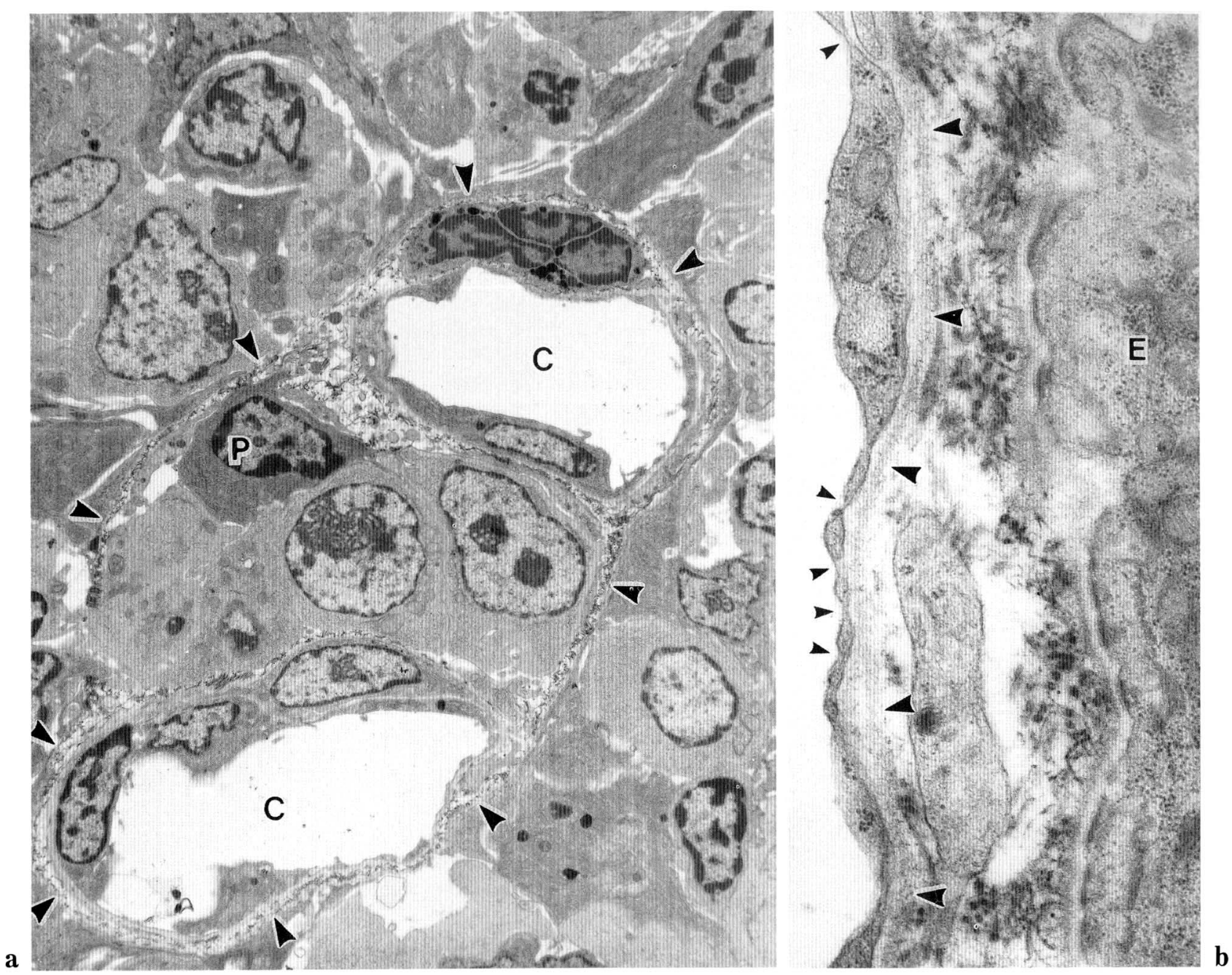

Fig. 5. TEM views of a transversely sectioned papilla projected into the crypt epithelium of a rabbit palatine tonsil. a. The papilla is delimited by densely stained collagen fibrils (arrowheads), and contains a pair of capillaries $(C)$, a plasma cell $(P)$ and some other cells. b. The capillary in the papilla is surrounded by the lamina densa (large arrowheads) and collagen fibrils. The endothelium has fenestrations with diaphragms (small arrowheads). There are many hemidesmosomes on the basal surface of the epithelium $(E)$ which are exposed to the lamina lucida of the basement membrane. $\mathrm{a}: \times 3,200, \mathrm{~b}: \times 32,000$

measuring about $10 \mathrm{~nm}$ in diameter and the other 60 $80 \mathrm{~nm}$ in diameter. Hemidesmosomes were observed on the basal surface of the stratified squamous epithelium contacting the underlying basement membrane. There were large capillaries immediately below the epithelial basement membrane, the diameter of these capillaries being $20-40 \mu \mathrm{m}$. The capillaries possessed their own basement membrane. The endothelial cells of these capillaries were attenuated except for their nuclear regions, and possessed numerous fenestrations with diaphragms (Fig. 4b). The endothelial cells had many microvilli projected into the capillary lumen (Fig. 4a). The collagen fibrillar layer surrounded the capillary with a basal lamina, i.e., the lamina densa of the basement membrane. Plasma cells were frequently observed around these capillaries.

The papillae located over the interfollicular area were surrounded by the epithelial basement membrane (Fig. 5). Within individual papillae were a pair of capillaries surrounded by their own basal laminae (Fig. 5a). Within the papillae, there were also collagen fibrils, reticular cells with long slender processes, macrophages and other free cells. The endothelial cells of the capillaries in the papillae that projected towards 
the reticulated epithelium were also attenuated and possessed diaphragms (Fig. 5b).

There were many papillae around the orifice of the crypt, whose epithelium showed typical stratified squamous cells. These papillae were also delimited by the epithelial basement membrane. The switchback capillaries in these papillae were surrounded by well-developed basal laminae, and their endothelial cells had fenestrations with a diaphragm. A collagen fibrillar layer lined the basal laminae of the epithelial cells of the capillaries.

\section{DISCUSSION}

We have demonstrated, by the alkali-water maceration/SEM method (OHTANI, 1987), the three-dimensional organization of the network of collagen fibrils (60-80 nm diameter) that position themselves immediately below the crypt epithelium of the palatine tonsil. Our TEM has shown that the lamina fibroreticularis of the crypt epithelial basement membrane consists of at least two kinds of collagen fibrils: thin ones of about $10 \mathrm{~nm}$ diameter stretching between the lamina densa (basal lamina) and thick ones of $60-80 \mathrm{~nm}$. Thus, the subepithelial collagen fibrils revealed under the SEM are thick collagen fibrils that constitute the lamina fibroreticularis of the epithelial basement membrane.

The present study clearly shows that the crypt epithelial basement membrane of the tonsil possesses numerous pores of various sizes $(0.5-20 \mu \mathrm{m}$ in diameter). The existence of basement membrane pores has been reported by others (YAMAGUCHI, 1960; KAWA. GUCHI, 1967a; KAWABATA, 1986; INAGA and TSUJITA, 1988). As shown in KAWAGUCHI's (1967a) and our own TEM observations, the pores are the sites through which free cells migrate. The high porosity of the epithelial basement membrane of the palatine tonsil seems to indicate that lymphocytes, macrophages and some other free cells actively migrate back and forth between the epithelium and the subepithelial region. Such porosity of the basement membrane seems to be a feature common to gut-associated lymphoid tissues (MCCLUGAGE and Low, 1984; MCClUGAGE, LOW and ZiMnY, 1986; OHTANI et al., in preparation). The morphological heterogeneity of the pores suggests that at any one time, pores are in different stages of formation or repair (GRENIER, MC. Clugage and Low, 1985). However, the mechanism by which the pores of the basement membrane are formed and repaired (or closed) is unknown.

It is worth noting that the basement membrane directly above the follicle is smooth but has many heterogeneous pores, while that over the interfollicular area forms many papillary projections, whose basement membrane possesses few pores. INAGA and TSUJiTA (1988), by removing epithelia, have also demonstrated papillae with few pores. KELEMEN $(1943,1954)$ suggested that papillae are formed when free cells actively migrate into the crypt epithelium. On the other hand, BoENNINGHAUS (1955) proposed that, as the secondary lymphoid follicle develops, the epithelium over the follicle is infiltrated by free cells and becomes wider: when free cells migrate more active$l y$, the epithelium around the papillae is also reticulated. Our results seem to support BoEnNinghaus's hypothesis, namely, the papillae of the palatine tonsil are initially formed as a structure characteristic of the stratified squamous epithelium, and with the development of secondary lymphoid follicles, the epithelium over the follicles becomes wider and at the same time reticulated through the infiltration of free cells, thus forming the highly reticulated dome-like epithelium over individual follicles. As more free cells migrate, the epithelium over the interfollicular area also becomes reticulated.

We have revealed that all the capillaries in the tonsil are surrounded by collagen fibrillar sheaths, and that the sheaths located below the collagen fibrillar sheet constitute the epithelial basement membrane. This indicates that all the capillaries in the tonsil are located below the epithelium. Thus, the term "intraepithelial" capillaries previously used by others (SchmedTJE and BATTS, 1973; KAWABATA, 1984) is misleading, and should be replaced by "subepithelial" capillaries.

Particularly noteworthy is the finding that the capillaries below the reticulated crypt epithelium are fenestrated sinusoids. KAWAGUCHI (1967a, b) has reported the existence of fenestrated capillaries in human tonsils. As reported by others (SCHMEDTJE and BATTS, 1973; FALK and MoOTZ, 1973; MoGI and MAEDA, 1978; MAEDA and MOGI, 1979), there are many immunoglobulin-containing plasma cells abutting on these sinusoids. Sinusoids, those with fenestrations in particular, facilitate the interchange between blood and tissues so that blood fluids and macromolecules can more readily pass back and forth between the two compartments. This therefore suggests that the subepithelial sinusoids of the tonsil are involved in taking up immunoglobulins secreted by plasma cells and certain other substances, as well as supplying the tissues with abundant oxygen and nutrients (OHTANI et al., 1989).

CURRAN and JONES (1977) have reported that many 
plasma cells and lymphocytes, $\mathrm{T}$ cells in particular, exist in the reticulated epithelium of the crypt. Immediately below the crypt epithelium are a few HEVs (TERASAWA et al., 1988) through which lymphocytes migrate into the lymphoid tissues (GowANs and KNIGHT, 1964; UMETANI, 1977). In this regard, the subepithelial sinusoids may also provide free cells with their migratory route out of the blood vessels.

Our previous studies have demonstrated that the HEVs in the interfollicular area are located downstream of the subepithelial capillaries (TERASAWA et al., 1988; OHTANI et al., 1989). As demonstrated here, the subepithelial capillaries are fenestrated sinusoids. Morphological studies have indicated that HEVs can appear not only in the secondary lymphoid tissues but also in any site in association with long-standing chronic inflammation (GRAHAM and SHANNON, 1972; FREEMONT, 1983; FREEMONT et al., 1983; FREEMONT and FORD, 1985; DuIJVESTIJN et al., 1988). It is also reported that lymphokine- or BCG-induced inflammation processes include the hypertrophy of postcapillary venules as well as the emigration of lymphocytes (DUMONDE et al., 1982; FREEMONT and FORD, 1985). Thus, as suggested in our previous study (OHTANI et al., 1989), these imply that some substances, presumably cytokines secreted by lymphocytes and/or macrophages, may be taken up by the sinusoidal capillaries and transported to the postcapillary venules. Such substances may induce the differentiation of HEVs, and thus maintain the follicles. However, it is not presently known how HEVs differentiated from postcapillary venules.

Acknowledgements. We would like to thank Dr. A. KikUTA, Department of Anatomy, Okayama University School of Medicine, for his critical discussions. Thanks are also due to Dr. K. TerasAWA, National Iwakuni Hospital, and Mr. N. Hayashi and Mr. N. Kishimoto, Central Research Laboratory, Okayama University School of Medicine, for their assistance with the electron microscopy.

\section{REFERENCES}

Anderson, J. C.: The response of the tonsil and associated lymph nodes of gnotobiotic piglets to the presence of bacterial antigen in the oral cavity. J. Anat. 117: 191198 (1974).

Boenninghaus, H.: Über den Retikulierungsvorgang am Epithel der Tonsille und die dabei auftretenden Veränderungen der Gitterfaserstruktur. Z. Laryngol. Rhinol. 34: 289-302 (1955).
Cooper, M. D., A. E. Gabrielsen, R. D. A. Peterson and R. A. Good: Ontogenic development of the germinal centers and their function-Relationship to the bursa of Fabricius. In: (ed. by) H. COTTIER, N. ODARTCHEnko, R. SchindleR and C. C. Congdon: Germinal centers in immune responses. Springer, New York, 1967 (p. 28-33).

Curran, R. C. and E. L. Jones: Immunoglobulin-containing cells in human tonsils as demonstrated by immunohistochemistry. Clin. Exp. Immunol. 28: 103-115 (1977).

Duijvestijn, A. M., E. H. Horst, S. T. Pals, B. N. Rouse, A. C. Steere, L. J. Picker, C. J. L. M. Meijer and E. C. Butcher: High endothelial differentiation in human lymphoid and inflammatory tissues defined by monoclonal antibody HECA-452. Amer. J. Pathol. 130: 147-155 (1988).

Dumonde, D. C., M. S. Pulley, F. J. Paradinas, B. M. SouthcotT, D. O'Connell, M. R. G. Robinson, F. Den Hollander and A. H. SchuURs: Histological features of skin reactions to human lymphoid cell line lymphokine in patients with advanced cancer. J. Pathol. 138: 289-308 (1982).

Falk, P. and W. Mootz: Morphologische Untersuchungen zur Retikulierung des Tonsillenepithels. Acta Otolarynogol. 75: 85-103 (1973).

FioretTi, A.: Die Gaumenmandel Darstellung der Biologie und Physiopathologie. G. Thieme, Stuttgart, 1961.

Freemont, A. J.: A possible route for lymphocyte migration into diseased tissues. J. Clin. Pathol. 36: 161-166 (1983).

Freemont, A. J. and W. L. Ford: Functional and morphological changes in post-capillary venules in relation to lymphocytic infiltration into BCG-induced granulomata in rat skin. J. Pathol. 147: 1-12 (1985).

Freemont, A. J., C. J. P. Jones, M. Bromley and P. ANDREws: Changes in vascular endothelium related to lymphocyte collections in diseased synovia. Arthritis Rheum. 26: 1427-1433 (1983).

GoLDNER, J.: A modification of the Masson trichrome technique for routine laboratory purposes. Amer. J. Pathol. 14: 237-243 (1938).

Gow ANS, J. L. and E. J. KNIGHT: The route of re-circulation of lymphocytes in the rat. Proc. Roy. Soc. B 159: 257-282 (1964).

GrahaM, R. C. and S. L. Shannon: Peroxidase arthritis: II. Lymphoid cell endothelial interactions during a developing immunologic inflammatory response. Amer. J. Pathol. 69: 7-24 (1972).

Grenier, C. P., S. G. McClugage and F. N. Low: A SEM study of the fibrous microskeleton of pores within epithelial basement membranes. Anat. Rec. 211: 73A (1985).

HowIE, A. J.: Scanning and transmission electron microscopy on the epithelium of human palatine tonsils. J. Pathol. 130: 91-98 (1980).

INAGA, K. and T. Tsujita: The structure of the human tonsillar basement membrane. Jap. J. Tonsil. 27: 7-11 (1988). 
KAWABATA, I.: Scanning electron microscopic studies of the human tonsil-Observations of the back surface of the tonsillar epithelium. Jap. J. Tonsil. 23: 6-11 (1984). : SEM observations of the surface of the tonsillar crypt epithelium. Jap. J. Tonsil. 25: 194-197 (1986).

KaWAGUCHI, E.: Ultrastructure of human palatine tonsil. I. Electron microscopic studies on tonsillar mucous epithelium. II. Electron microscopic studies on tonsillar lymphatic tissue. Sapporo Med. J. 31: 144-165, 166-179 (1967a, b).

Kelemen, G.: Pathway of the tonsillar lymphocyte. Arch. Otolaryngol. 38: 433-444 (1943).

: Histological test of tonsillar activity based on the reticulo-epithelial interplay. Arch. Otolaryngol. 59: 263-281 (1954).

LuFT, J. H.: Improvements in epoxy resin embedding methods. J. Biophys. Biochem. Cytol. 9: 409-414 (1961).

MAEDA, S. and G. Mogi: Ultrastructure of human tonsillar crypts. II. Chronic tonsillitis. Jap. J. Tonsil. 18: 28-36 (1979).

McClugage, S. G. and F. N. Low: Microdissection by ultrasonication: Porosity of the intestinal epithelial basal lamina. Amer. J. Anat. 171: 207-216 (1984).

McClugage, S. G., F. N. Low and M. L. ZimnY: Porosity of the basement membrane overlying Peyer's patches in rats and monkeys. Gastroenterology 91: 1128-1133 (1986).

Mogi, G. and S. MAEDA: The function of tonsillar crypts. Jap. J. Tonsil. 17: 211-221 (1978).

Murakami, T.: A metal impregnation method of biological specimens for scanning electron microscopy. Arch. Histol. Jap. 35: 323-326 (1973).

OHTANI, O.: Three-dimensional organization of the connective tissue fibers of the human pancreas: A scanning electron microscopic study of $\mathrm{NaOH}$ treated tissues. Arch. Histol. Jap. 50: 557-566 (1987).

Ohtani, O., T. Ushiki, T. Taguchi and A. KikUta: Collagen fibrillar networks as skeletal frameworks: A demonstration by cell-maceration/scanning electron microscope method. Arch. Histol. Cytol. 51: 249-261 (1988).
Ohtani, O., A. Kikuta, K. Terasawa, T. Higashikawa, T. Yamane, T. Taguchi, Y. Masuda and T. MuraKAMI: Microvascular organization of human palatine tonsils. Arch. Histol. Cytol. 52: 493-500 (1989).

OWen, R. L. and P. Nemanic: Antigen processing structures of the mammalian intestinal tract: an SEM study of lymphoepithelial organs. Scanning Electron Microscopy/1978/II: 367-378 (1978).

SchmedTJE, J. F. and A. F. BATTs: Immunoglobulins and blood vessels in the tonsillar crypt epithelium. Ann. Otol. Rhinol. Laryngol. 82: 359-369 (1973).

Terasawa, K., O. Ohtani, A. Kikuta, T. Taguchi, Y. MASUdA, S. KAW AKAMI and Y. OGURA: Microvascular organization of the rabbit tonsil-A scanning electron microscopic study of corrosion casts. Jap. J. Tonsil. 27: 18-22 (1988).

Umetani, Y.: Postcapillary venule in rabbit tonsil and entry of lymphocytes ionto its endothelium: A scanning and transmission electron microscope study. Arch. Histol. Jap. 40: 77-94 (1977).

YAMAGUCHI, Y.: Histopathological studies on the subepithelial basement membrane of the palatine tonsils. J. Otolaryngol. Jap. 63: 122-132 (1960).

Dr. Osamu OHTANi

Department of Anatomy

Okayama University School of Medicine

Shikata-cho 2-5-1

Okayama, 700 Japan

大谷修

700 岡山市鹿田町 2-5-1

岡山大学医学部

第二解剖学教室 